\title{
Osler-Weber-Rendu Syndrome: A Rare Cause of Iron Deficiency
}

\author{
Abdullah Ozkok, MD, Timur Selcuk Akpinar, MD, and Vakur Akkaya, MD
}

Istanbul Faculty of Medicine, Department of Internal Medicine, Istanbul University, Istanbul, Turkey.

J Gen Intern Med 26(9): 1077

DOI: $10.1007 / \mathrm{s} 11606-011-1680-2$

(c) Society of General Internal Medicine 2011

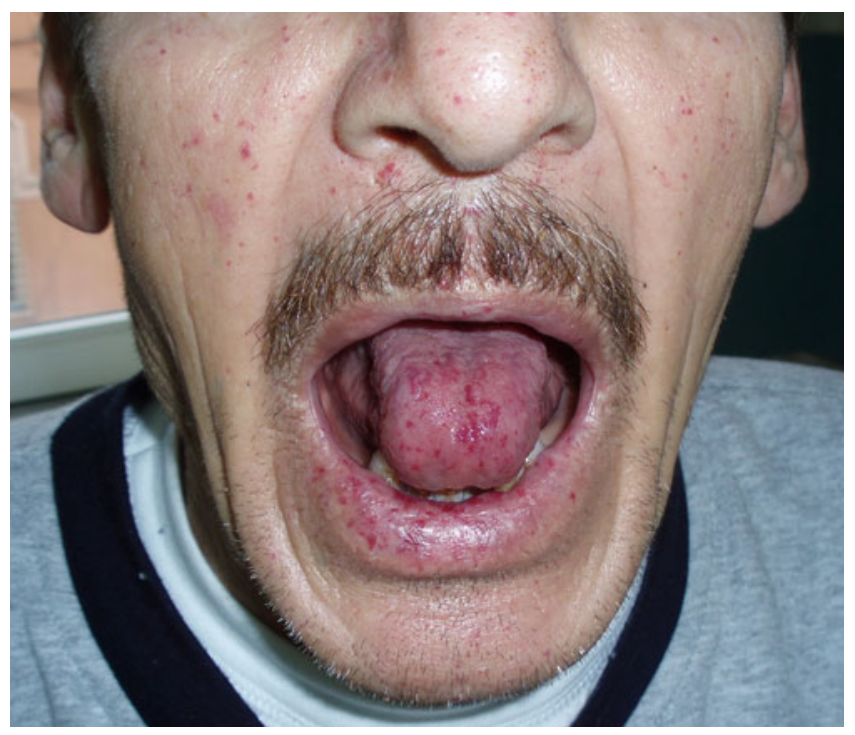

Figure 1. Multiple telangiectasias on the patient's face, lips, and tongue.

A 52-year-old man with frequent epistaxis presented with fatigue and exertional dyspnea. On physical examination, multiple telangiectasias were noted on the patient's face, lips, tongue (Fig. 1), and finger tips (Fig. 2). Laboratory analysis demonstrated iron deficiency anemia (hemoglobin, $8.2 \mathrm{~g} / \mathrm{dl}$; ferritin: $15 \mathrm{ng} / \mathrm{ml}$ ). Colonoscopy revealed multiple colonic telengiectasias, and endoscopic hemostatic treatment was performed on bleeding lesions.

Osler-Weber-Rendu syndrome (OWR), also known as hereditary hemorrhagic telangiectasia, is an autosomal dominant disease that affects all ethnic and racial groups with an overall

Received November 16, 2010

Accepted February 17, 2011

Published online March 5, 2011

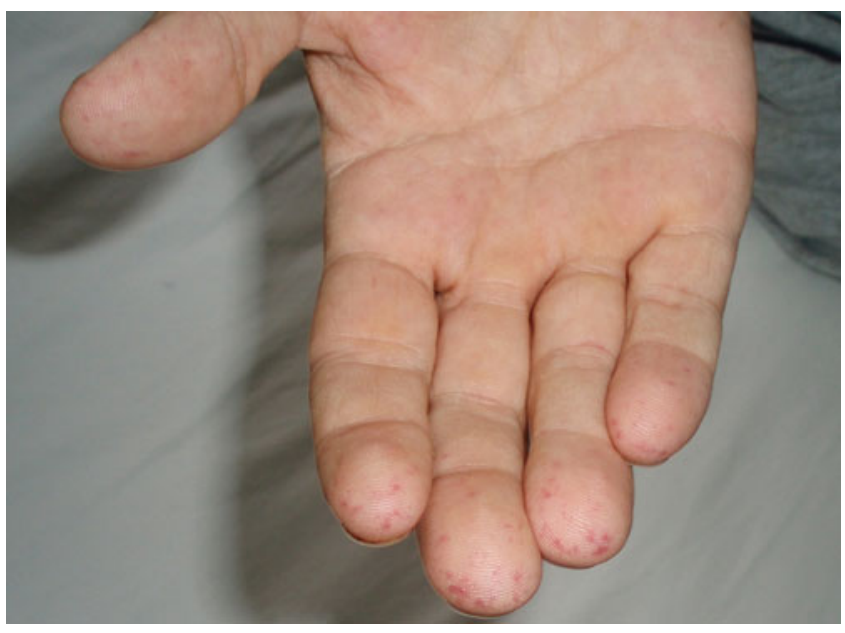

Figure 2. Multiple telangiectasias on the patient's finger tips.

frequency of 1 per 5,000 to 10,000 persons. Although the number and location of lesions vary widely, most telangiectasias are found in the oral, nasal, and gastrointestinal mucosa, as well as the fingertips, whereas arteriovenous malformation occurs most commonly in the lungs, liver, and central nervous system. The prevalence of intestinal telangiectasia varies from $10 \%$ to $33 \%$ in patients with OWR. Approximately $25 \%$ of individuals older than 60 years present with melena or anemia. Endoscopic ablation using electrocoagulation or laser techniques is useful for control of gastrointestinal bleeding in the short term. ${ }^{1}$

Informed Consent: Informed consent was obtained from the patient to have his picture taken and information about his case published.

Conflict of Interest: None disclosed.

Corresponding Author: Abdullah Ozkok, MD; Istanbul Faculty of Medicine, Department of Internal Medicine, Istanbul University 34390 Fatih Istanbul, Turkey (e-mail: abdullahozkok@yahoo.com).

\section{REFERENCES}

1. Sharathkumar AA, Shapiro A. Hereditary haemorrhagic telangiectasia. Haemophilia. 2008;14(6):1269-80. Review. 